\title{
ANALISA CLOCK GENERATOR PADA \\ RANGKAIAN POWER SUPPLY UNTUK APLIKASI TRIGER IC TTL DILABORATORIUM DIGITAL PROGRAM STUDI TEKNIK ELEKTRONIKA DI POLITEKNIK NEGERI MALANG
}

\author{
Hariyanto A.Md, Rosita Ferdiyana SST. \\ Jurusan Teknik Elektro, Politeknik Negeri Malang \\ hariyantopolinema@gmail.com
}

(Artikel diterima: Oktober 2019, direvisi: September 2019, diterima untuk terbit: Januari 2020)

\begin{abstract}
Abstrak - The good performance of a clock generator circuit in the power supply for triger TTL IC is very influential on the success of the lab. A series. Therefore, the effectiveness of use must be adapted to its use in the practicum. To create a clock generator circuit as a source of pulses from a digital counter IC, a timer IC can be used. This pulse generator or clock generator can be used for clock sources in making counters up and down. Clock generators are often referred to as clock generators. The pulse generator in making the circuit is often used linear integrated circuit (IC: Integrated Circuit). A linear IC that is commonly used in general is usually the NE555 which is a timer IC. As a timer it can also be used analogically as a Clock Generator or pulse generator which can generally generate the frequency or time as needed.
\end{abstract}

Kata kunci: clock generator,trigger, power supply, TTL

\section{Pendahuluan}

Clock Generator sering disebut sebagai pembangkit pulsa (clock). Pembangkit pulsa dalam pembuatan rangkaiannya sering digunakan rangkaian terpadu linear (IC: Integrated Circuit) . IC linear yang sering digunakan secara umum biasanya NE555 yang merupakan IC pewaktu (Timer). Sebagai timer secara analogi dapat juga digunakan sebagai Clock Generator atau pembangkit pulsa yang pada umumnya dapat membangkitkan frekuensi atau waktu sesuai dengan yang diperlukan.

\section{A. Clock Generator pada power supply untuk trigger IC TTL}

Clock Generator sering disebut sebagai pembangkit pulsa (clock). Pembangkit pulsa dalam pembuatan rangkaiannya sering digunakan rangkaian terpadu linier IC ( integrated Circuit. IC adalah komponen dasar yang terdiri dari resistor,transistor dan lain lain. IC merupakan komponen yang dipakai sebagai otak elektronika. Kemajuan teknologi ini tidak terlepas dari adanya kemajuan dibidang pengetahuan dan pengolahan bahan semi konduktor kususnya pada silokon. IC ditemukan oleh Jack Kirby pada tahun 1958 di Laboratorium Texas Instrumen. Pengembangan IC tidak terlepas dari transistor. Kelebihan dari IC ini adalah merupakan bahan semikonduktor, kelebihan dari bahan semi konduktor adalah memiliki sifat konduktivitas sifat penghantar listrik).Secara umum jenis IC ada 2 macam.yaitu IC Digital dan IC linier. (1)

IC linear yang sering digunakan secara umum biasanya NE555 yang merupakan IC pewaktu (Timer). Sebagai timer secara analogi dapat juga digunakan sebagai Clock Generator atau pembangkit pulsa yang pada umumnya dapat membangkitkan pulsa frekuensi sesuai yang diperlukan.Pembangkit pulsa IC 555 merupakan chip yang didesain khusus untuk pembangkit pulsa yang dapat diatur mode kerjanya, sehingga dapat membentuk suatu multivibrator dan timer. Pembangkit pulsa IC 555 banyak dikembangkan oleh beberapa pabrik, dimana tiap pabrik memiliki kode produksi masing-masing.

Rangkaian blok diagram clok generator untuk trigger ic TTL

\section{TINJAUAN PUSTAKA}

\section{A. Clock Generator pada power supply untuk trigger IC TTL}

Clock Generator sering disebut sebagai pembangkit pulsa (clock). Pembangkit pulsa dalam pembuatan rangkaiannya sering digunakan rangkaian terpadu linier IC ( integrated Circuit. IC adalah komponen dasar yang terdiri dari resistor,transistor dan lain lain. IC merupakan komponen yang dipakai sebagai otak elektronika. Kemajuan teknologi ini tidak terlepas dari adanya kemajuan dibidang pengetahuan dan pengolahan bahan semi konduktor kususnya pada silokon. IC ditemukan oleh Jack Kirby pada tahun 1958 di Laboratorium Texas Instrumen. Pengembangan IC tidak terlepas dari transistor. Kelebihan dari IC ini adalah merupakan bahan semikonduktor, kelebihan dari bahan semi konduktor adalah memiliki sifat konduktivitas sifat penghantar listrik).Secara umum jenis IC ada 2 macam.yaitu IC Digital dan IC linier.

IC linear yang sering digunakan secara umum biasanya NE555 yang merupakan IC pewaktu(Timer). Sebagai timer secara analogi dapat juga digunakan sebagai Clock Generator atau pembangkit pulsa yang pada umumnya dapat membangkitkan pulsa frekuensi sesuai yang diperlukan.Pembangkit pulsa IC 555 merupakan chip yang didesain khusus untuk pembangkit pulsa yang dapat diatur mode kerjanya, sehingga dapat membentuk suatu multivibrator dan timer. Pembangkit pulsa IC 555 banyak dikembangkan oleh beberapa pabrik, dimana tiap pabrik memiliki kode produksi masing-masing. 


\section{Metode Penelitian}

Untuk Untuk memberikan contoh hal-hal yang perlu diketahui dalam proses penelitian ini dan memudahkan mengimplementasikan tujuan penelitian ada beberapa hal yang akan disampaikan meliputi : jenis, tempat, variable, instrument, dan desain riset semua penelitian. Jenis penelitian ini ditinjau dari tujuan penggunaan maka penelitian yang akan dilakukan adalah jenis penelitian terapan (applied research) karena produk dari penelitian ini bisa dipakai oleh mahasiswa. Sedangkan ditinjau dari metodenya maka jenis penelitian ini adalah eksperimental karena akan dilakukan beberapa kali percobaan untuk mendapatkan nilai veriabel yang diharapkan

\section{A. Tempat Penelitian}

Penelitian dilaksanakan di Laboratorium Elektronika Jurusan Teknik Elektro Politeknik Negeri Malang

\section{B. Riset Aksi}

Riset aksi diawali dengan pengumpulan tools yang digunakan dalam penelitian, serta mengguji media penyimpanan dengan berbagai volume penyimpanan, pengambilan /analisis data hingga membuat kesimpulan didiskripsikan dengan diagram alir seperti pada Gambar dibawah in

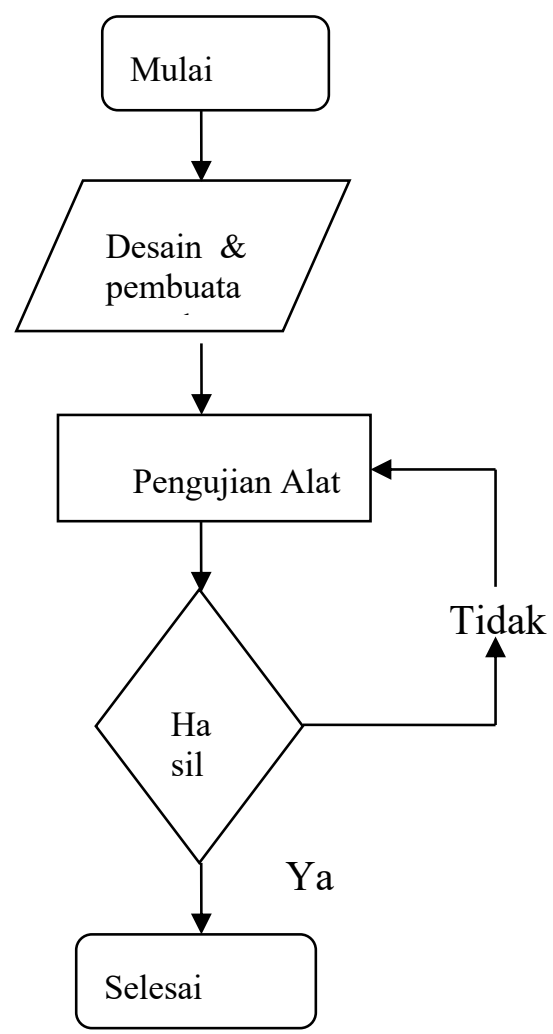

Gambar 1. Diagram Alir Riset

\section{Desain Riset}

Desain riset akan memberikan diskripsi detail pelaksanaan keseluruhan langkah penelitian dalam kerangka pencapaian tujuan riset. Dalam hal ini urutan pelaksanaan penelitian diawali dengan studi literatur, riset aksi. Desain modul clock generator

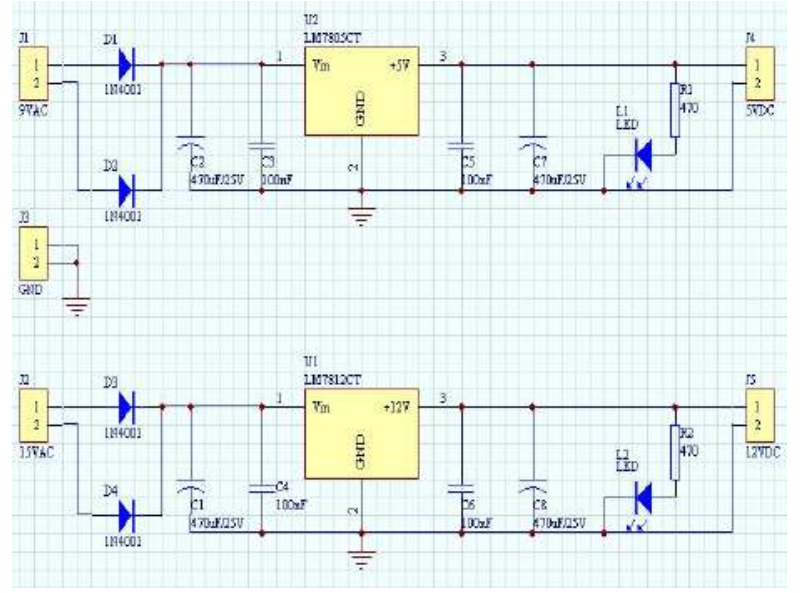

Gambar 3. Skema Rangkaian Power supply

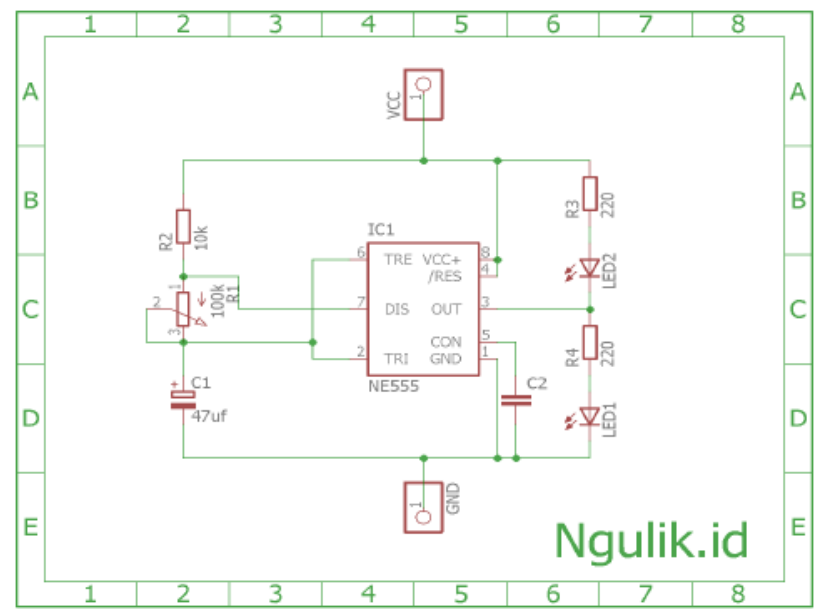

Gambar 4. Rangkaian Clock Generator

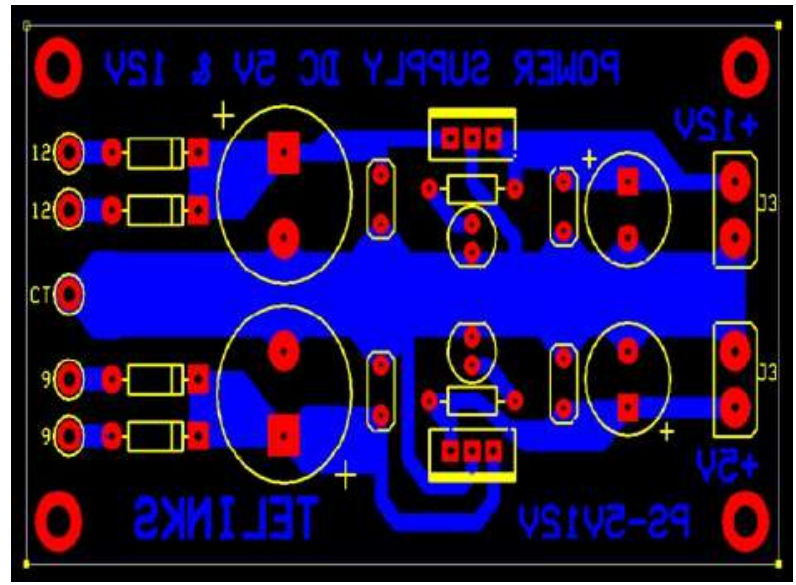

Gambar 5. Lay out Power Supply 


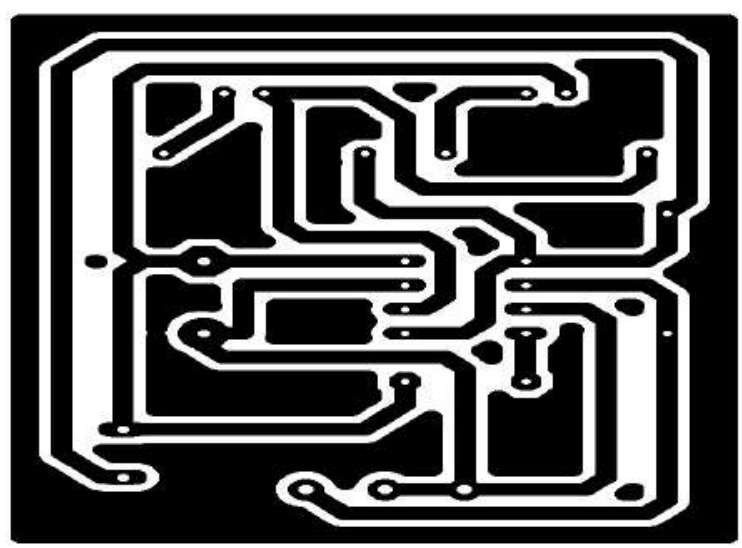

Gambar 6 Lay out Clock Generator

\section{Pengujian Penelitian}

Beberapa hal yang perlu diperhatikan sebelum melakukan pengujian pada penelitian ini adalah harus memperhatikan faktor kesehatan dan keselamatan kerja antara lain :

- Selalu berdoa sebelum melakukan kegiatan.

- Memeriksa terlebih dahulu semua komponen aktif maupun pasif sebelum digunakan.

- Memeriksa pengkabelan rangkaian

- Membaca dan memahami petunjuk penggunaan komponen berdasarkan datashett komponen. .

- Dalam menyusun rangkaian, harus memperhatikan letak kaki-kaki komponen.

- Memastikan bahwa alat alat ukur yang akan digunakan dalam kondisi baik.

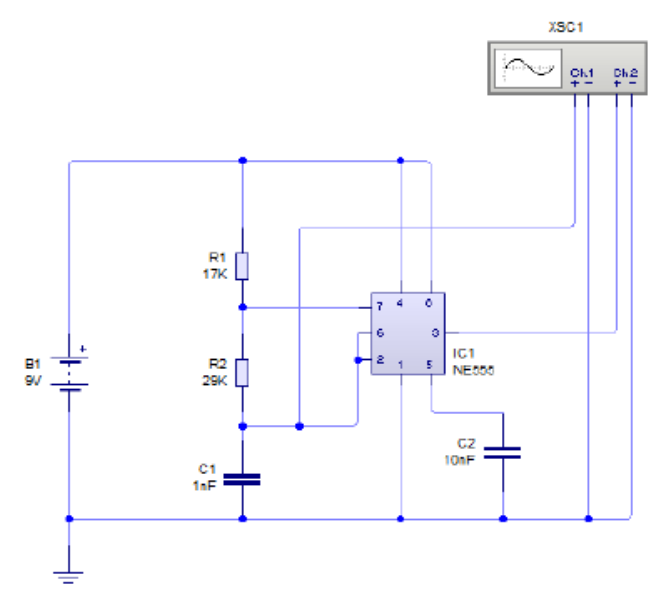

Gambar 2. Konfigurasi pengujian clock generator

\section{Hasil Penelitian dan Pembahasan}

\section{A. Data Analisa Hasil Pengujian}

Dari hasil penelitian serta pengujian menggunakan Osciloskop sebagai alat ukur dapat diketahu bentuk Gelombang gerator berupa gelombang kotak

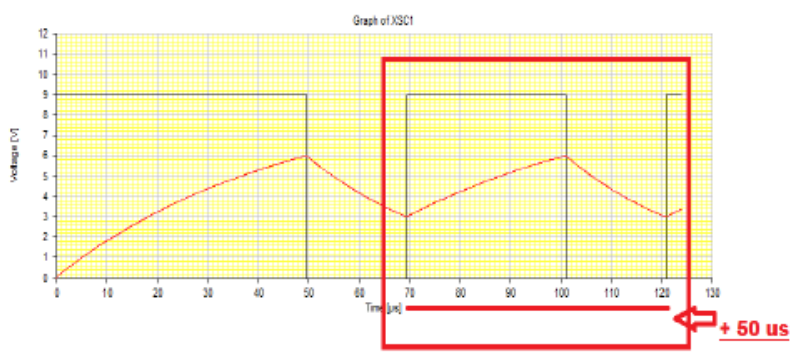

Gambar 4.1 gambar pengukuran gelombang output

\section{B. Analisa Data}

\begin{tabular}{|l|l|l|l|l|}
\hline & 1 & 2 & 3 & 4 \\
\hline RA & $6,8 \mathrm{k} \Omega$ & $180 \mathrm{k} \Omega$ & $180 \mathrm{k} \Omega$ & $470 \mathrm{k} \Omega$ \\
\hline RB & $6,8 \mathrm{k} \Omega$ & $180 \mathrm{k} \Omega$ & $470 \mathrm{k} \Omega$ & $470 \mathrm{k} \Omega$ \\
\hline $\begin{array}{l}\text { Nyala } \\
\text { LED }\end{array}$ & Redup & Agak terang & Terang & $\begin{array}{l}\text { Terang dan } \\
\text { berkedip }\end{array}$ \\
\hline Ton & $\begin{array}{l}1036,728 \\
\times 10^{-6}\end{array}$ & $21344,4 \times 10^{-6}$ & $\begin{array}{l}49549,510 \\
\times 10^{-6}\end{array}$ & $\begin{array}{l}71656,2 \\
\times 10^{-6}\end{array}$ \\
\hline Toff & $\begin{array}{l}518,364 \\
\times 10^{-6}\end{array}$ & $13721,4 \times 10^{-6}$ & 35828,1 & $\begin{array}{l}35828,1 \\
\times 10^{-6}\end{array}$ \\
\hline T & $\begin{array}{l}1555,092 \\
\times 10^{-6}\end{array}$ & $35065,8 \times 10^{-6}$ \\
\hline F & 643,049 & 28,5178 & $\begin{array}{l}85377,6 \\
\times 10^{-6}\end{array}$ & $\begin{array}{l}107484,3 \\
\times 10^{-6}\end{array}$ \\
\hline DC & 0,667 & 0,6087 & 0,580 & 9,303 \\
\hline
\end{tabular}

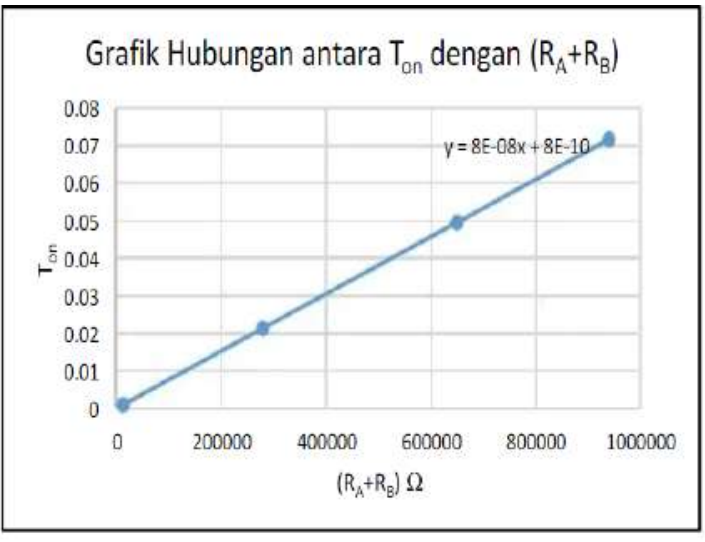

Gambar 4.1 Grafik hubungan antara $\mathrm{T}$ on dengan $(\mathrm{Ra}=\mathrm{RB})$ 


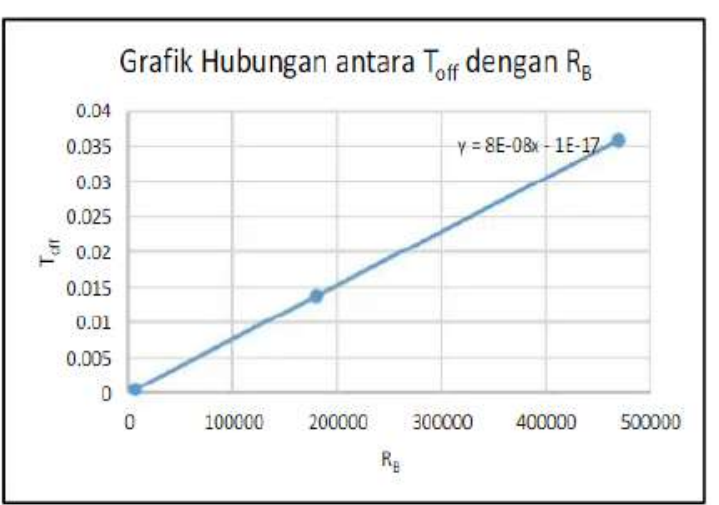

Gambar 4.2 Grafik hub antara T of dengan RS

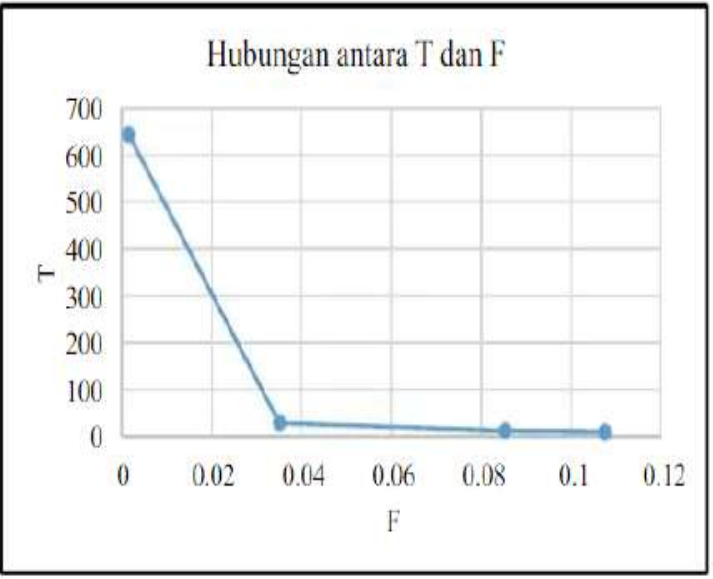

Gambar 4.3 Grafik hubungan antara T dan F

1. Analisis $\mathrm{T}_{\mathrm{0}}$

Dalam praktikum kali ini menggunakan empat pasang resistor, yaitu:

a. $R_{\mathrm{A}}=6,8 \mathrm{k} \Omega$ dan $\mathrm{R}_{\mathrm{B}}=6,8 \mathrm{k} \Omega$,

b. $R_{A}=100 \mathrm{k} \Omega$ dan $R_{B}=180 \mathrm{k} \Omega$,

c. $R_{A}=180 \mathrm{k} \Omega$ dan $R_{B}=470 \mathrm{k} \Omega$,

d. $\mathrm{RA}=470 \mathrm{k}$ Ohm dan $\mathrm{Ra}=470 \mathrm{k} \mathrm{Ohm}$

Dalam pengujian ini menggunakan kapasitor dengan nilai $100 \mathrm{nF}$ dan $\mathrm{nF}$, sehingga diperoleh besar $\mathrm{T}$ on:

\begin{tabular}{|c|c|c|c|}
\hline \multirow{2}{*}{ No } & \multicolumn{2}{|c|}{ Resistor } & \multirow{2}{*}{$\mathrm{T}_{\text {on }}$} \\
\cline { 2 - 3 } & $\mathrm{R}_{\mathrm{A}}$ & $\mathrm{R}_{\mathrm{B}}$ & \\
\hline 1 & $6800 \Omega$ & $6800 \Omega$ & 0,001036728 \\
\hline 2 & $100000 \Omega$ & $180000 \Omega$ & 0,0213444 \\
\hline 3 & $180000 \Omega$ & $470000 \Omega$ & 0,049549510 \\
\hline 4 & $470000 \Omega$ & $470000 \Omega$ & 0,0716562 \\
\hline
\end{tabular}

Dari data tersebut diperoleh bahwa hasil pengamatan tersebut sesuai dengan terori, yaitu besar kecilnya $T_{\text {on }}$ dipengaruhi oleh besar $\mathrm{R}_{\mathrm{A}}, \mathrm{R}_{\mathrm{B}}$ dan kapasitor yang digunakan dalam rangkaian tersebut, sesuai dengan persamaan :

$$
T_{o n}=0,693\left(R_{A}+R_{B}\right) C
$$

Pada grafik 1. Hubungan antara $T_{\text {on }}$ dengan $R_{A}+R_{B}$ dengan kapasitor $110 \mathrm{nF}$ memiliki persamaan yaitu $\mathrm{Y}=8 \times 10^{-8} x+8 \mathrm{E}-10$ yang menunjukkan bahwa semakin besar penjumlahan dari $\mathrm{R}_{\mathrm{A}}$ dan $R_{13}$, maka semakin besar pula nilai dari $T_{\text {on }}$. Sedangkan nilai dari 8 $\times 10^{-8}$ merupakan perkalian dari 0.693 dengan kapasitor.

2. Analisis $\mathrm{T}_{\text {off }}$

Dalam praktikum yang telah dilakukan, diperoleh bahwa besar $\mathrm{T}_{\text {off }}$ adalah :

\begin{tabular}{|l|l|l|}
\hline No & \multicolumn{1}{|c|}{$\mathrm{R}_{\mathrm{B}}$} & \multicolumn{1}{c|}{$\mathrm{T}_{\text {off }}$} \\
\hline 1 & $6800 \Omega$ & 0,000518364 \\
\hline 2 & $180000 \Omega$ & 0,0137214 \\
\hline 3 & $470000 \Omega$ & 0,0358281 \\
\hline 4 & $470000 \Omega$ & 0,0358281 \\
\hline
\end{tabular}

Dari data tersebut diperoleh bahwa nilai $\mathrm{T}_{\text {off }}$ dipengaruhi oleh besar $\mathrm{R}_{\mathrm{B}}$ dan nilai kapasitor dalam rangkaian, hal ini sesuai dengan teori persamaan :

$$
\mathrm{T}_{\text {off }}=0.693 \mathrm{R}_{\mathrm{B}} \mathrm{C}
$$

Dan dari grafik yang dibuat berdasarkan data tersebut diperoleh persamaan $\mathrm{Y}=8 \times 10^{-8} x-10^{-17}$ yang menunjukkan bahwa semakin besar nilai $\mathrm{R}_{\mathrm{B}}$ maka nilai $\mathrm{T}_{\text {off }}$ akan semakin besar. Sedangkan gradien dalam grafik tersebut yaitu $8 \times 10^{-8} x$ merupakan hasil kali dari 0,693 dengan besar nilai kapasitor.

3. Analisis Hubungan $T$ dan $F$

Nilai $T$ dapat diperoleh dari penjumlahan antara $T_{\text {on }}$ dan $T_{\text {off }}$, sehingga besar nilai $T$ bergantung pada besar nilai $T_{\text {on }}$ dan $T_{\text {off. }}$.

\section{KESIMPULAN DAN IMPLIKASI}

a) Pembangkit clock ne 555 akan menghasilkan sinyal kotak atau persegi dimana sinyal ini digunakan pada kebanyakan rangkaian digital

b) Untik mentriger sebuah rangkain digital menggunakan IC TTL agar dapat

bekerja diperlukan sebuah pembangkit pulsa yang disebut juga dengan clock generator 


\section{Saran}

1). Clock Generator ini masih belum sempurna..untuk pengembangan kedepan perlu adanya penyempurnaan rangkaian untuk mendapatkan output gelombang yang bervariasi frekuensinya.

2). Untuk mendapatkan hasil yang lebih optimal disarankan untuk kedepannya desain clock generator untuk catuan IC TTL dapat dirancang menggunakan jenis IC yang mempunyai kesempurnaan lebih baik dalam mengeluarkan gelombang output.

\section{DAFTAR PUSTAKA}

[1] Zaki M. H., (2007) Cara Mudah Belajar Merangkai Elektronika Dasar Lanjutan

[2] Susa'at, S. 199. OP Amp dan IC Linear. Malang: Direktorat Pendidikan Dasar dan Menengah PPPGT/VEDC Malang

[3] Putra, Indra Wijaya. 2014. Timer NE555. Artikel Penelitian.Tangerang: Sekolah Tinggi Keguruan dan Ilmu Pendidikan Surya http://www.academia.edu/15288987/Laporan_Praktikum_Tim erNE555

[4] Dickson Khomponen Elektronika

[5] (http://elektronika-dasar.web.id/) 